\title{
AYA Biblioteca: investigação para a encontrabilidade da informação étnico-racial
}

\author{
Aya Biblioteca: research for the ethnic-racial information findability \\ Arthur Ferreira Campos \\ Doutorando em Ciência da Informação \\ Universidade Federal da Paraíba \\ arthurfcampos94@gmail.com \\ Erinaldo Dias Valério \\ Doutor em Ciência da Informação \\ Universidade Federal de Goiás \\ erinaldodias@ufg.br
}

\section{Resumo}

Apresenta a AYA Biblioteca, do Laboratório de Estudos Pós-Coloniais e Decoloniais da Universidade do Estado de Santa Catarina, como um ambiente informacional que promove a encontrabilidade da informação étnico-racial. Objetiva aplicar o checklist para avaliação do ambiente informacional digital da AYA Biblioteca, identificando os atributos da Encontrabilidade da Informação existentes e indicando sugestões para melhorias, na perspectiva do/a usuário/a. Para tanto utiliza uma pesquisa exploratória, de abordagem qualitativa, para a investigação de facilidades, dificuldades e possíveis otimizações quanto a encontrabilidade da informação étnico-racial na AYA Biblioteca. Relaciona, numa dimensão prática, os estudos em encontrabilidade da informação e os estudos das relações étnicoraciais. Mediante aplicação do checklist, sugere um olhar aos atributos: "folksonomia", devido a variedade cultural, para a população negra e para a população indígena, gerando nuvem de tags proveniente da navegação social; "metadados", o que engajaria o alcance dos materiais informacionais disponíveis por motores de busca; "wayfinding", visto que o ambiente não gera marcadores de orientação espacial. Conclui que a AYA Biblioteca é um ambiente informacional digital que contribui para a visibilidade da população negra e da população indígena, tendo um papel favorável na agenda antirracista, podendo ser uma fonte de informação para o ensino da História e Cultura Afro-brasileira e Africana em instituições, conforme a Lei 10.639/2003. Para isso, é necessário adequar-se aos atributos de encontrabilidade da informação, principalmente a partir da criação de um vocabulário controlado, nuvem de tags e o uso de uma plataforma que permita a inserção de metadados.

\section{Palavras-chave}

Relações raciais. Encontrabilidade da Informação. Encontrabilidade da Informação étnico-racial. Informação étnico-racial.

\begin{abstract}
It presents the AYA Biblioteca, of the Laboratório de Estudos Pós-Coloniais e Decoloniais da Universidade do Estado de Santa Catarina, as an informational environment that promotes the information findability of ethnic-racial information. It aims to apply the checklist to assess the digital informational environment of the AYA Biblioteca, identifying the existing Information Findability attributes and suggesting suggestions for improvements, from the user's perspective. It is an exploratory research, with a qualitative approach, for the investigation of facilities, difficulties and possible optimizations regarding the ethnic-racial information findability in the AYA Biblioteca. It lists, in a practical dimension, studies on information findability and studies on ethnic-racial relations. Through the application
\end{abstract}


of the checklist, it suggests a look at the attributes: "folksonomy", due to the cultural variety, for the black population and for the indigenous population, generating a tag cloud from social navigation; "Metadata", which would engage the reach of informational materials available by search engines; "wayfinding", since the environment does not generate spatial orientation markers. AYA Biblioteca is a digital informational environment that contributes to the visibility of the black population and the indigenous population, having a favorable role in the anti-racist agenda, and can be a source of information for the teaching of Afro-Brazilian and African History and Culture in institutions, according to the brazilian Law 10.639/2003. For this, it is necessary to adapt to the attributes of information findability, mainly from the creation of a controlled vocabulary, tag cloud and the use of a platform that allows the insertion of metadata.

\section{Keywords}

Race relations. Information findability. Ethnic-racial information findability. Ethnic-racial information.

\section{INTRODUÇÃO}

O racismo no Brasil tem possibilitado o crescimento de desigualdades em vários âmbitos sociais e, para isso, é necessário desenvolver mecanismos para combatê-lo. Entendemos, que a educação, por meio de ações pedagógicas, pode ser um dos caminhos para a redução de preconceitos, discriminações e racismos que afetam grupos historicamente discriminados, promovendo o avanço social. O movimento negro brasileiro, por exemplo, contribui para esse avanço denunciando práticas racistas e propondo uma agenda com os conhecimentos produzidos pela população negra em prol de uma educação antirracista. No campo educacional, a aprovação da Lei 10.639/2003, resultante das articulações e estratégias do movimento negro, torna obrigatório o ensino da História e Cultura Afro-brasileira nas diversas instituições de ensino fundamental e médio, particulares ou públicos.

No ano de 2004, a partir da Lei 10.639/2003, tivemos as Diretrizes Curriculares Nacionais para a Educação das Relações Étnico-Raciais e para o Ensino de História e Cultura AfroBrasileira e Africana, CNE/CP 003/2004 e CNE/CP Resolução 1/2004. É importante destacar que essa Lei foi a primeira a incluir a discussão racial na Lei de Diretrizes e Bases da Educação Nacional e a exigir a inserção dessas discussões nas instituições de Ensino Superior no país.

Desse modo, pesquisadores/as e cientistas, estudantes, professores/as e intelectuais que trabalham com a problemática das relações raciais, em diversas áreas do conhecimento, dedicam-se a estudar e a propor direcionamentos pedagógicos em busca de políticas que tornem efetiva uma educação antirracista. Isso porque o racismo no Brasil é estrutural e se manifesta de diferentes formas.

Observamos, no momento de pesquisa para a construção deste artigo, a existência de algumas iniciativas no país que tem avançado com ações antirracistas, contribuindo na formação de pesquisadores/as. Face a isso, nosso campo de investigação é o website da AYA Biblioteca ${ }^{1}$. Esse ambiente informacional digital é vinculado ao Laboratório de Estudos Póscoloniais e Decoloniais da Universidade do Estado de Santa Catarina. É uma fonte de informação que, mediante os recursos das Tecnologias de Informação e Comunicação (TIC), propõe-se a disponibilizar informação sobre os estudos africanos e sobre os estudos indígenas, por meio de conhecimento acadêmico, científico e social.

\footnotetext{
${ }^{1}$ Disponível em: https://ayalaboratorio.com. Acesso em: 30 mar. 2021.
} 
Navegar, acessar e usar ambientes informacionais digitais, como a AYA Biblioteca, exige certo conhecimento prévio para manuseio de ferramentas. Entendemos, nesse contexto, que é necessário que o sujeito conheça e saiba usar instrumentos tecnológicos a seu favor, mas, se os ambientes informacionais digitais fossem pensados e estruturados mediante subsídios que indiquem a informação de forma mais explícita, a encontrabilidade da informação não exigiria tantas habilidades informáticas, por exemplo.

Vechiato (2013) aponta que a Encontrabilidade da Informação (EI) é um estudo inserido no campo da Ciência da Informação que se relaciona com o comportamento dos sujeitos e as funcionalidades dos ambientes informacionais. Em outras palavras, é a possibilidade do sujeito encontrar uma informação. Difere-se da recuperação da informação, ao passo que a El procura estudar e propor subsídios para facilitar a disposição de informações em ambientes informacionais.

Já a recuperação da informação é uma particularidade do sistema, ou seja, o sistema recupera a informação a partir da indexação, de metadados, de taxonomias, de folksonomias e de outros mecanismos de representação da informação estruturados pelo/a profissional que o administra (ROA-MARTíNEZ, 2019); a Encontrabilidade, dessa forma, é um construto que procura enfatizar o sujeito facilitando seu acesso e uso conforme as funcionalidades do ambiente informacional.

O objetivo do estudo é aplicar o checklist para avaliação do ambiente informacional digital da AYA Biblioteca, identificando os atributos da Encontrabilidade da Informação existentes e indicando sugestões para melhorias, na perspectiva do/a usuário/a. Esse instrumento foi proposto por Vechiato, Oliveira e Vidotti (2016) no contexto dos ambientes informacionais híbridos e o adaptamos especificamente para nossa investigação, visando sinalizar possíveis ferramentas que auxiliem no acesso e uso da informação pelos sujeitos. O estudo se justifica na possibilidade de investigar uma análise que facilite a encontrabilidade de informações de forma rápida e intuitiva na AYA Biblioteca. Esta pesquisa foi desenvolvida no âmbito do grupo de pesquisa Alaye - Laboratório de Pesquisa em Informação Antirracista e Sujeitos Informacionais da Faculdade de Informação e Comunicação (FIC) da Universidade Federal de Goiás (UFG).

Para esta pesquisa, no âmbito da Ciência da Informação, utilizamos o conceito de "informação étnico-racial" que, segundo Oliveira (2009, p. 56), é "todo elemento inscrito num suporte físico (tradicional ou digital), passivo de significação linguística por parte dos sujeitos que a usam[...]". O autor complementa que além disso, esse elemento tem o potencial de produzir conhecimento a partir de questões históricas e culturais para afirmação de um grupo étnico.

Desse modo, consideramos o conceito de informação étnico-racial para um grupo específico, que é a população negra. Tais informações procuram reduzir discriminações, preconceitos e racismos que afetam às pessoas negras, procurando dar visibilidade positiva e reconstruir novos saberes.

Para tanto, este artigo está estruturado em 5 seções. Na seção 2, discorrermos sobre a Encontrabilidade da Informação e dialogamos com teóricos/as dessa abordagem de estudo, compreendendo a AYA Biblioteca como um ambiente informacional digital; na seção 3, descrevemos nossos procedimentos metodológicos; na seção 4, apresentamos a análise e a discussão dos resultados e na seção 5, apontamos nossas considerações finais. 


\section{ENCONTRABILIDADE DA INFORMAÇÃO}

A El contempla bases teóricas e epistemológicas relacionadas ao comportamento dos sujeitos e os recursos provenientes dos sistemas de informação e dos ambientes informacionais (VECHIATO; VIDOTTI, 2014). Campos e Vechiato (2020, p. 552) salientam que as pesquisas em encontrabilidade da informação "surgem devido o ser humano buscar e se orientar por mecanismos ao seu redor, tanto na perspectiva informacional quanto na perspectiva urbana/ambiental". Essa compreensão é oriunda de findability, que emprega a: qualidade que um objeto possui para ser localizado ou recuperado; o grau no qual um determinado objeto pode ser fácil de ser descoberto ou recuperado; e o grau em que um sistema ou ambiente suporta navegação e recuperação (MORVILLE, 2005, tradução nossa).

Campos, Sousa e Oliveira (2021) ressaltam que quando o sujeito pensa na possibilidade de encontrar uma informação, pressupõe-se que o ambiente informacional digital deve entregar a informação localizável e estruturada de forma compreensível. A encontrabilidade está relacionada às TIC, direcionando-as para os estudos com ambientes informacionais. Diferente dos estudos em findability, a El é direcionada para o contexto informacional, focando no sujeito e em suas características de buscar, orientar-se e acessar as funcionalidades de um ambiente (VECHIATO, 2013).

Morville (2005) considera findability para a qualidade de buscar, encontrar e usar a informação em âmbito web, porém, as pesquisas em El incorporam a web e compreendem análises em ambientes informacionais analógicos, digitais e híbridos, podendo avançar para além da web e/ou além do digital. Vechiato e Vidotti (2014) destacam a necessidade da participação dos sujeitos na classificação e no compartilhamento da informação para o desenvolvimento tecnológico, como por exemplo, a construção de folksonomias, nuvens de tags e outros instrumentos favoráveis à El.

Existem atributos que promovem a El em ambientes informacionais, tais como: taxonomias navegacionais; instrumentos de controle terminológico; folksonomias; metadados; affordances; wayfinding; descoberta de informações; acessibilidade e usabilidade; mediação dos/as informáticos e dos/as profissionais da informação; mediação dos sujeitos informacionais; intencionalidade (VECHIATO, 2013; VECHIATO; VIDOTTI, 2014). Por uma questão didática, trataremos dos conceitos destes atributos durante a aplicação do checklist ao analisarmos a AYA Biblioteca na seção 5. Esse checklist é um instrumento de avaliação de ambientes informacionais híbridos, proposto por Vechiato, Oliveira e Vidotti (2016), convergindo a El e a Arquitetura da Informação Pervasiva (AIP). Adaptamos esse instrumento para análise do ambiente informacional digital AYA Biblioteca.

Investigamos atributos na AYA Biblioteca sob a perspectiva de que o sujeito pode acessar esse ambiente através de dispositivos diversos, como smartphone, tablet ou o computador, necessitando assim dos estudos em AIP, para os atributos: responsividade, ubiquidade, placemaking, redução e resiliência, correlação e a pervasidade (VECHIATO; OLIVEIRA; VIDOTTI, 2016). A pervasividade, segundo Campos e Oliveira (2020) é uma característica da informação e envolve uma experiência de propagação por diferentes meios e canais, como os ambientes informacionais. Os atributos da Encontrabilidade da Informação e da Arquitetura da Informação Pervasiva estão dispostos nos Quadros 1, 2, 3 e 4. Utilizaremos a seção da análise e aplicação do checklist para explicitá-los.

Apresentamos na subseção 2.1 sobre o que são ambientes informacionais. De certo, a AYA Biblioteca é um ambiente informacional que dissemina materiais e recursos informacionais advindos das pesquisas do Laboratório de Estudos Pós-Coloniais e Decoloniais da 
UDESC. Inferimos, então, que a informação se espalha e se propaga do Laboratório (ambiente informacional analógico que trabalha com materiais informacionais diversos, de cunho arquivístico e biblioteconômico) para a AYA Biblioteca (ambiente informacional digital que subsidia a disseminação dos materiais do Laboratório supracitado para a sociedade, mediante os recursos da web), caracterizando um comportamento pervasivo.

Estando esses materiais disponíveis na web, o acesso online é possibilitado mediante dispositivos tecnológicos que suportem um tipo de navegador (por exemplo, Google Chrome, Mozila Firefox, Safari, Microsoft Edge, entre outros), caracterizando novamente um comportamento pervasivo referente a propagação dos conteúdos disseminados pela AYA Biblioteca.

\subsection{AYA Biblioteca em contexto aos ambientes informacionais}

Os ambientes informacionais são lugares de informação onde o sujeito acessa, usa e interage com diversos elementos, ferramentas e mecanismos que o auxiliam no processo de recuperação e de Encontrabilidade da Informação. Compreendemos que, ao navegar num ambiente informacional, o sujeito navega, busca, acessa, recupera e encontra um material ou um recurso informacional. Esse processo também conta com os aspectos cognitivos e com a competência em informação.

Os ambientes informacionais contemplam as esferas analógica, digital ou híbrida. Conforme Vechiato, Oliveira e Vidotti (2016, p. 59), nos analógicos, "a informação possui natureza analógica bem como os suportes de armazenagem"; nos digitais, "estão as informações de natureza digital, que suscita armazenamento em suportes também digitais"; e nos híbridos, é comportado "ambos os tipos de informação e ambos os tipos de suportes". A AYA Biblioteca assume características de ambiente informacional digital, tendo como objetivo

\footnotetext{
[...]divulgar e deixar acessível materiais audiovisuais, iconográficos e escritos cujas temáticas se referem às histórias das Áfricas e Indígenas. Além disso, estaremos divulgando materiais didáticos que estão sendo desenvolvidos pelas ações de extensão do laboratório, bem como seus projetos de pesquisa. Dentro desta proposta do site do AYA pretende se disponibilizar produções que operem de forma conjunta razão e emoção sem hierarquizar o saber e o sentir, alinhando os distintos conhecimentos existentes em nossa sociedade, o que pensamos consistir em uma nova forma imprescindível de enfrentamento a um pensamento hegemônico (AYA BIBLIOTECA, 2021, online).
}

A AYA Biblioteca nos disponibiliza digitalmente materiais advindos de atividades, ações e iniciativas realizadas no contexto analógico do Laboratório de Estudos Pós-Coloniais e Decoloniais da UDESC, ou seja, como o próprio website nos informa, a AYA Biblioteca é um dos produtos do referido Laboratório. Observamos, de acordo com o website da AYA Biblioteca (2021, online), que o ambiente opera como uma Biblioteca Virtual. Porém, consideramos que sendo as informações dispostas e disponíveis no ambiente informacional do Laboratório de Estudos Pós-Coloniais e Decoloniais e disseminadas em contexto digital, a AYA Biblioteca é uma biblioteca digital que integra informações vinculadas a um domínio. Para definir essa identidade, consideramos que a AYA Biblioteca é uma biblioteca digital caracte- 
rizando um ambiente informacional digital. Observamos também que ela utiliza a plataforma WordPress², não operando como um blog.

\section{PROCEDIMENTOS METOdOLÓGICOS}

Nossos procedimentos metodológicos são estruturados conforme a execução do objetivo que propomos. Realizamos uma pesquisa de abordagem qualitativa que, segundo Minayo (2009), caracteriza-se como uma pesquisa social. Quanto ao objetivo, realizamos uma pesquisa exploratória que, segundo Moresi (2003), procura construir aportes para conhecimentos pouco explorados. Nesse contexto, observamos uma necessidade em relacionarmos os estudos sobre as relações étnico-raciais com as Tecnologias de Informação e Comunicação para analisarmos um ambiente informacional digital destinado a pesquisadores/as, estudantes, professores/as e a comunidade em geral com informações étnico-raciais sobre grupos historicamente discriminados, como as populações negras e indígenas.

Mediante os estudos em encontrabilidade da informação, de Vechiato e Vidotti (2014), iniciamos um diálogo voltado a Encontrabilidade da Informação étnico-racial, procurando trabalhar ambos as abordagens, aproximando os estudos em TIC e os estudos sobre as relações raciais. Segundo Oliveira e Aquino (2012, p. 487-488), a informação étnico-racial é aquela produzida para a "promoção da igualdade racial na sociedade brasileira e, dentre outras políticas, que tratam e regulam as relações étnicas baseadas na diversidade brasileira". Escolhemos a AYA Biblioteca devido o seu potencial educacional e de aprendizagem, como também a sua importância para a agenda antirracista.

Esse ambiente informacional digital apresenta um conjunto de materiais voltados para produção de conhecimento e de cultura no contexto das relações raciais. A AYA Biblioteca também se preocupa em atender as diretrizes da Lei $11.645 / 2008$, elencando o reconhecimento e a contribuição das populações negras e indígenas para a formação da sociedade brasileira.

Desse modo, um ambiente informacional digital que armazena informações especializadas no contexto aqui explicado, pode atender a quarta Lei da Biblioteconomia - poupe o tempo do leitor - compreendida por Ranganathan (2009), que visa diminuir o tempo necessário para um sujeito encontrar a informação de que necessita. Destacamos também a incipiência de ambientes informacionais digitais que cumprem o mesmo papel da AYA Biblioteca no âmbito da agenda antirracista.

Procuramos então entender mecanismos que favorecem a navegação e busca no referido ambiente, assim como a Encontrabilidade e a descoberta de informações. Na seção subsequente, aplicamos o checklist já citado nesta pesquisa, proposto por Vechiato, Oliveira e Vidotti (2016) para avaliar ambientes informacionais híbridos e, partindo da contribuição desses/as estudiosos/as, o adaptamos para a análise específica deste ambiente informacional digital. Com isso, investigamos a AYA Biblioteca conforme os subsídios que contribuem para a Encontrabilidade da Informação étnico-racial.

\section{APLICAÇÃO DO CHECKLIST MEDIANTE A INVESTIGAÇÃO DA ENCONTRABILIDADE DA IN- FORMAÇÃO ÉTNICO-RACIAL NA AYA BIBLIOTECA}

\footnotetext{
2 Plataforma livre e aberta para gerenciamento de conteúdos específicos na web. Cria páginas pessoais, organizacionais, institucionais, blogs, entre outras.
} 
Reunimos nesta seção os resultados oriundos da aplicação do checklist de Vechiato, Oliveira e Vidotti (2016), para análise dos dados e discussão dos resultados. Organizamos os atributos em quatro quadros para facilitar a visualização e organização do artigo: o Quadro 1 apresenta os atributos "Taxonomias navegacionais"; "Instrumentos de controle terminológico"; "Folksonomias" e "Metadados"; já o Quadro 2 apresenta "Mediação dos sujeitos informacionais"; "Affordances"; "Wayfinding" e "Descoberta de informações"; no Quadro 3 é disposto "Acessibilidade e Usabilidade"; "Intencionalidade"; "Responsividade e Ubiquidade"; e, por último, o Quadro 4 apresente "placemaking"; "Redução e Resiliência"; "Correlação" e "Pervasividade".

Quadro 1 - Avaliação das "taxonomias navegacionais", "instrumentos de controle terminológico", "folksonomias" e "metadados"

\begin{tabular}{|c|c|c|}
\hline Atributo & Checklist & $\begin{array}{l}\text { Sim (S) } \\
\text { Não (N) } \\
\text { Parcialmente apli- } \\
\text { cável (P) } \\
\text { Não aplicável (NA) }\end{array}$ \\
\hline \multirow{2}{*}{$\begin{array}{l}\text { Taxonomias navega- } \\
\text { cionais }\end{array}$} & $\begin{array}{l}\text { a) A taxonomia navegacional existente possui categoriza- } \\
\text { ção adequada dos conceitos/termos. }\end{array}$ & $S$ \\
\hline & $\begin{array}{l}\text { b) A taxonomia navegacional existente possui termos } \\
\text { significativos e coerentes que não dificultam seu enten- } \\
\text { dimento. }\end{array}$ & $S$ \\
\hline $\begin{array}{l}\text { Instrumentos de } \\
\text { controle terminoló- } \\
\text { gico }\end{array}$ & $\begin{array}{l}\text { a) São utilizados vocabulários controlados, tesauros e/ou } \\
\text { ontologias para a representação do assunto dos recursos } \\
\text { informacionais. }\end{array}$ & $\mathrm{N}$ \\
\hline \multirow{2}{*}{ Folksonomias } & $\begin{array}{l}\text { a) Há recursos de classificação social (folksonomia) que } \\
\text { favoreçam a participação dos sujeitos informacionais. }\end{array}$ & $\mathrm{N}$ \\
\hline & $\begin{array}{l}\text { b) As tags geradas pelos sujeitos são disponibilizadas em } \\
\text { nuvem de tags para facilitar a navegação social. }\end{array}$ & $\mathrm{N}$ \\
\hline \multirow{2}{*}{ Metadados } & $\begin{array}{l}\text { a) Os recursos informacionais estão representados por } \\
\text { metadados. }\end{array}$ & $\mathrm{N}$ \\
\hline & $\begin{array}{l}\text { b) É utilizado padrão de metadados coerente com a pro- } \\
\text { posta do ambiente informacional. }\end{array}$ & $\mathrm{N}$ \\
\hline
\end{tabular}

Fonte: Adaptado de Vechiato, Oliveira e Vidotti (2016).

Para o atributo - "Taxonomias navegacionais", observamos que: a) O website apresenta organização adequada no Menu de navegação. Constatamos também que a navegação atribui descrição como legendas nas fotos e indicativos para recursos audiovisuais, para leitura, atividades de grupo de estudos, entre outros; b) $\mathrm{O}$ ambiente apresenta termos e expressões que favorecem o entendimento e a visibilidade de diferentes culturas. Apresentamos na Figura 1 a interface da AYA Biblioteca, demonstrando o menu de navegação e a aba de busca simbolizada numa "lupa". 
Figura 1 - Homepage da AYA Biblioteca

\section{AYA BIBLIOTECA}

LABORATÓRIO DE ESTUDOS PÓS-COLONIAIS E DECOLONIAIS

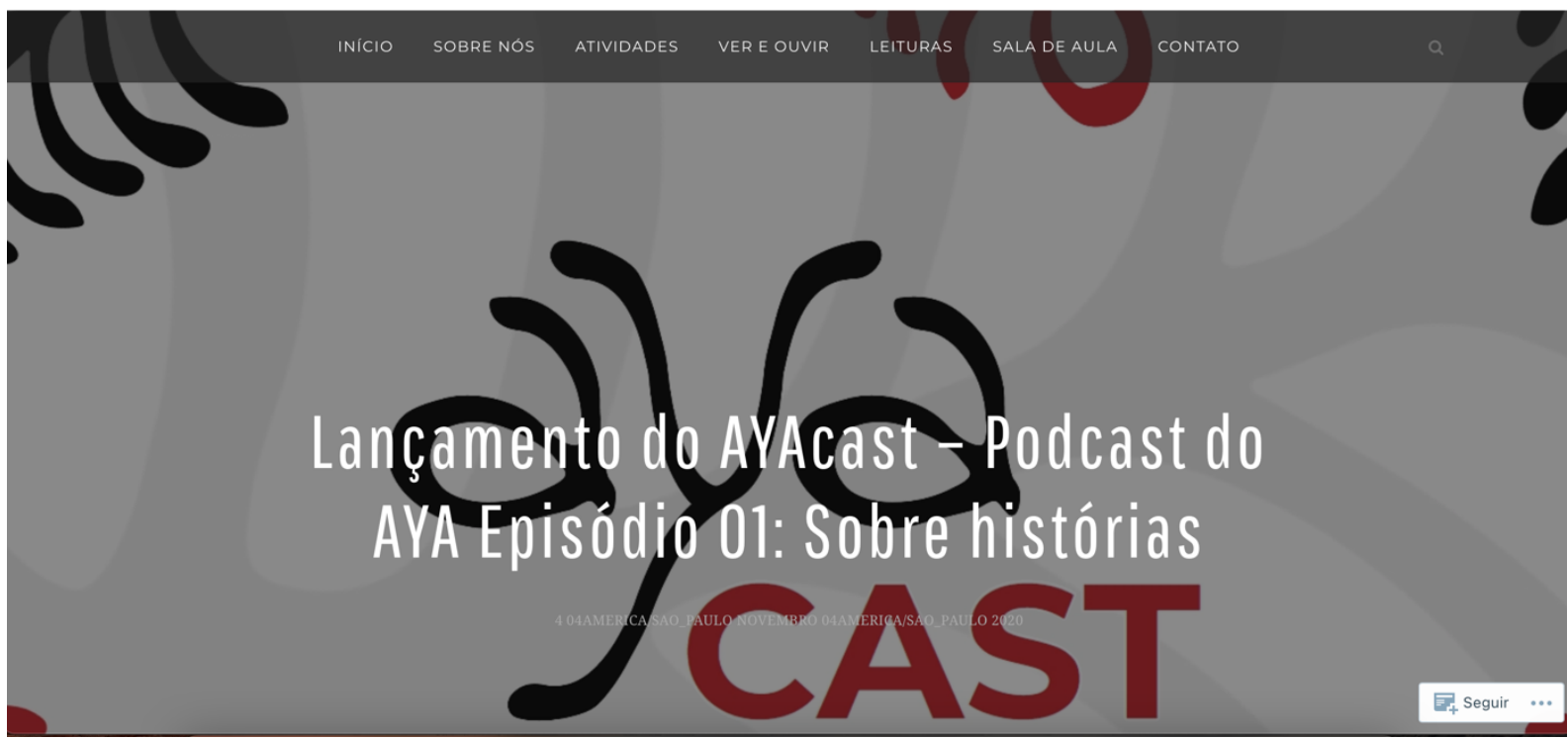

Fonte: Extraído da AYA Biblioteca (2021).

Para o atributo- "Instrumentos de controle terminológico": a) Na plataforma WordPress, os instrumentos de indexação são livres e mediados por quem insere as postagens. Percebemos que os recursos de busca, portanto, vasculham todo o documento a fim de encontrarem similaridades entre os resultados e o termo buscado pelo sujeito. Isso pode tornar exaustivos os resultados buscados. Como sugestão, os/as gestores/as poderiam pensar num vocabulário controlado que permita sugestões quando um sujeito insere um determinado termo na aba buscar. Isso pode refinar a busca tornando os resultados mais específicos e satisfatórios. A relevância da construção de um vocabulário controlado específico sobre as relações étnico-raciais viabilizaria a valorização da identidade da população negra e indígena. Desse modo, é indispensável que os sujeitos que construirão essa ferramenta sejam munidos de conhecimento sobre esses grupos para evitarem a reprodução de preconceitos, discriminações e racismo, que tem colocado esses grupos na invisibilidade. A informação étnico-racial propõe uma visibilidade positiva apresentando as contribuições desses grupos para a sociedade. A Figura 2 demonstra um pouco da variedade dos materiais disponíveis na AYA Biblioteca. Ao clicarmos em "Leituras" na homepage, fomos direcionados a "Categoria: Para Ler". 
Figura 2 - Categoria: Para ler

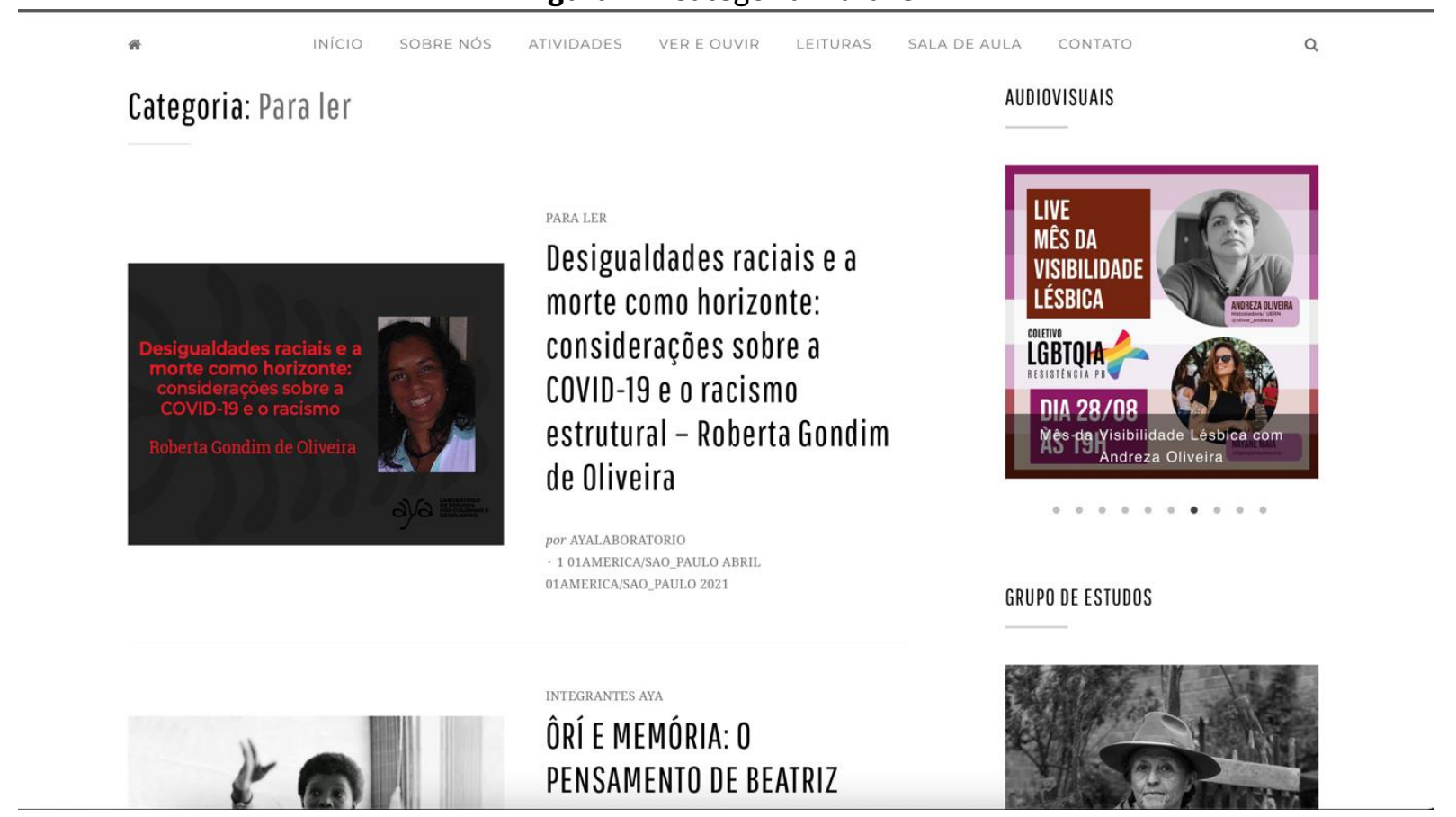

Fonte: Extraído da AYA Biblioteca (2021).

No atributo - "Folksonomias", a) Entendemos que a folksonomia seja vista como parcial, visto que, a AYA Biblioteca possui vastos materiais culturais específicos em suas postagens. Dessa forma, o/a mediador/a da postagem precisará de um entendimento prévio da comunidade usuária; b) Esse recurso é interessante para ser inserido ao ambiente, assim como a classificação social das postagens, o que geraria uma nuvem de tags dos termos mais buscados pelos sujeitos no ambiente.

No atributo - "Metadados", a) - A inserção de metadados na plataforma WodPress é limitada. $\mathrm{O}$ ambiente vasculha o conteúdo dos documentos a partir do termo buscado pelo sujeito. Caso fosse possibilitada a inserção de metadados, a AYA Biblioteca teria mais alcance em grandes buscadores, como o Google; b) - O padrão de metadados não é utilizado porque não há a possibilidade de inserção de metadados para cada postagem. 
Quadro 2 - Avaliação da "mediação dos sujeitos informacionais", "affordances", "wayfinding" e "descoberta de informações"

\begin{tabular}{|c|c|c|}
\hline Atributo & Checklist & $\begin{array}{l}\text { Sim (S) } \\
\text { Não (N) } \\
\text { Parcialmente aplicável (P) } \\
\text { Não aplicável (NA) }\end{array}$ \\
\hline \multirow[b]{2}{*}{$\begin{array}{l}\text { Mediação dos sujeitos } \\
\text { informacionais }\end{array}$} & $\begin{array}{l}\text { a) Os sujeitos participam da produção da } \\
\text { informação disponibilizada. }\end{array}$ & $\mathrm{N}$ \\
\hline & $\begin{array}{l}\text { b) Os sujeitos participam da organização / } \\
\text { representação da informação disponibili- } \\
\text { zada. }\end{array}$ & $\mathrm{N}$ \\
\hline Affordances & $\begin{array}{l}\text { a) As afforfances aplicadas facilitam o } \\
\text { entendimento por diferentes tipos de } \\
\text { sujeitos informacionais. }\end{array}$ & $S$ \\
\hline Wayfinding & $\begin{array}{l}\text { a) O ambiente utiliza marcos e/ou metáfo- } \\
\text { ras que dão pistas ao sujeito para orientá- } \\
\text { lo no espaço digital. }\end{array}$ & $\mathrm{N}$ \\
\hline \multirow{3}{*}{$\begin{array}{l}\text { Descoberta de informa- } \\
\text { ções }\end{array}$} & $\begin{array}{l}\text { a) O mecanismo de busca utiliza o recurso } \\
\text { autocomplete ou autossugestão. }\end{array}$ & $N$ \\
\hline & $\begin{array}{l}\text { b) Na página com os resultados de busca } \\
\text { são apresentadas facetas para o refina- } \\
\text { mento da pesquisa. }\end{array}$ & $N$ \\
\hline & $\begin{array}{l}\text { a) Os resultados de busca apresentam } \\
\text { diversos tipos de documentos com base na } \\
\text { estratégia de busca inicial do sujeito, apre- } \\
\text { sentando-os de forma relacionada. }\end{array}$ & $S$ \\
\hline
\end{tabular}

Fonte: Adaptado de Vechiato, Oliveira e Vidotti (2016).

No atributo - "Mediação dos sujeitos informacionais", a) identificamos que não existem ferramentas que possibilitem a participação dos sujeitos na produção da informação disponibilizada. Entendemos que a AYA Biblioteca é um produto extensionista do Laboratório de Estudos Pós-Coloniais e Decoloniais, portanto, há apenas a participação das pessoas do grupo; b) ressaltamos que a participação de sujeitos externos poderia ser a partir das mídias sociais utilizadas pela AYA Biblioteca, o Instagram ${ }^{3}$ e o Facebook ${ }^{4}$, como forma de aproximação com o público que se interessa pelas temáticas. Essas mídias sociais possibilitam diversas maneiras de interação e participação dos/as seguidores/as para exposição de opiniões, ideias e sugestões de conteúdos para disseminação.

No atributo - "Affordances", a) observamos que a navegação gera pistas que facilitam o entendimento dos sujeitos quanto ao que o ambiente oferece. Essas pistas visíveis são: a lupa para busca de materiais informacionais; a 'casa' em referência a homepage ou 'voltar para o início'; a opção 'voltar para o topo' representada por uma seta para cima quando navegamos até a parte inferior das páginas, entre outros. Essas pistas podem facilitar e agilizar a navegação, contribuindo para a encontrabilidade de informações.

No atributo - "Wayfinding", a) notamos que o ambiente não gera marcadores de orientação espacial para o sujeito. A necessidade de caminhos que indiquem onde o sujeito está, de onde ele veio e onde ele pode ir é importante em qualquer ambiente informacional. Campos e Vechiato (2020, p. 568) conceituam que wayfinding, atributo da Encontrabilidade da Informação, está "ligado a outros atributos como a usabilidade, a acessibilidade, as affordances e a descoberta de informações, promovendo a autonomia de busca pelo sujeito".

\footnotetext{
${ }^{3}$ Disponível em: https://www.instagram.com/ayalaboratorio/

${ }^{4}$ Disponível em: https://www.facebook.com/ayalaboratorio/
} 
Desse modo, os elementos de wayfinding podem gerar caminhos de orientação subjetivos para esse ambiente informacional digital.

No atributo - "Descoberta de informações", a) percebemos que o mecanismo de busca não utiliza autocomplete para facilitar o processo de busca pelo sujeito. Autocomplete ou autossugestão é um recurso, comumente utilizado no Google e em ambientes ecommerce, que gera sugestões de busca conforme o sujeito digita um determinado termo a ser buscado. Isso facilita a descoberta de informações que incialmente não estavam sendo pensadas para a busca; b) não visualizamos facetas quando o ambiente gera os resultados e nem possibilidades de refinamento da pesquisa, mas c) o ambiente apresenta diversos tipos de documentos relacionados a partir dos resultados de busca.

Quadro 3 - Avaliação da "acessibilidade e usabilidade", "intencionalidade", "responsividade" e "ubiquidade"

\begin{tabular}{|c|c|c|}
\hline Atributo & Checklist & $\begin{array}{l}\text { Sim (S) } \\
\text { Não (N) } \\
\text { Parcialmente aplicável (P) } \\
\text { Não aplicável (NA) }\end{array}$ \\
\hline \multirow{3}{*}{$\begin{array}{l}\text { Acessibilidade e Usabili- } \\
\text { dade }\end{array}$} & a) O ambiente possui usabilidade. & $\mathrm{S}$ \\
\hline & $\begin{array}{l}\text { b) O ambiente digital possui recursos de } \\
\text { acessibilidade digital na interface. }\end{array}$ & $\mathrm{N}$ \\
\hline & $\begin{array}{l}\text { c) Foram utilizadas as recomendações de } \\
\text { acessibilidade da World Wide Web Consor- } \\
\text { tium -W3C (WCAG 2.0). }\end{array}$ & $\mathrm{N}$ \\
\hline Intencionalidade & $\begin{array}{l}\text { a) Há indicativos de que o ambiente se } \\
\text { preocupa com a intencionalidade dos } \\
\text { sujeitos por meio de tecnologias como } \\
\text { análise de log de interação ou outras. }\end{array}$ & $\mathrm{N}$ \\
\hline \multirow[b]{2}{*}{ Responsividade } & a) Possui interface responsiva. & $\mathrm{S}$ \\
\hline & $\begin{array}{l}\text { b) Permite a continuidade das ações dos } \\
\text { sujeitos informacionais entre os diferentes } \\
\text { dispositivos. }\end{array}$ & NA \\
\hline Ubiquidade & $\begin{array}{l}\text { a) Há indicativos de que o ambiente possui } \\
\text { tecnologias ubíquas. }\end{array}$ & NA \\
\hline
\end{tabular}

Fonte: Adaptado de Vechiato, Oliveira e Vidotti (2016).

No atributo - "Acessibilidade e Usabilidade", a) constatamos que o ambiente contempla a usabilidade e interação conforme a navegação, porém b) não possui recursos de acessibilidade e c) nem foram utilizadas as recomendações da W3C. Sugerimos que o ambiente possibilite aumentar e diminuir o tamanho da fontes das letras, possibilite a adaptação do contraste da harmonia de cores da tela para sujeitos com baixa visão e disponibilize um recurso de leitura das páginas e leitura de imagens para sujeitos deficientes visuais. Isso contribuirá para a inclusão de sujeitos específicos.

No atributo - "Intencionalidade", a) não visualizamos análises de log de interação e nem nuvem de tags com os termos mais buscados pelos sujeitos, fazendo com que a preocupação com a intencionalidade do sujeito seja limitada conforme os indicativos deste checklist. Porém, destacamos que para a visualização e engajamento desse ambiente informacional digital a análise de logs e nuvem de tags é válida para identificar a intencionalidade e participação dos sujeitos.

No atributo - "Responsividade", a) observamos que a AYA Biblioteca possui interface responsiva em smartphones, tablets e demais dispositivos tecnológicos, adaptando-se a telas de diferentes dimensões; b) a continuidade de ações dos sujeitos entre diferentes dispo- 
sitivos não é aplicável a AYA Biblioteca visto que seu papel é estritamente informacional e disseminador. A continuidade de tarefas seria aplicável se o ambiente utilizasse serviços de empréstimo de materiais e o sujeito os reservasse pela plataforma e realizasse o empréstimo no ambiente informacional analógico do Laboratório. A Figura 3 ilustra a interface desse ambiente informacional digital acessado por um smartphone.

Figura 3 - AYA Biblioteca acessada por smartphone

\section{AYA BIBLIOTECA}

\section{LABORATÓRIO DE ESTUDOS PÓS-COLONIAIS E DECOLONIAIS}
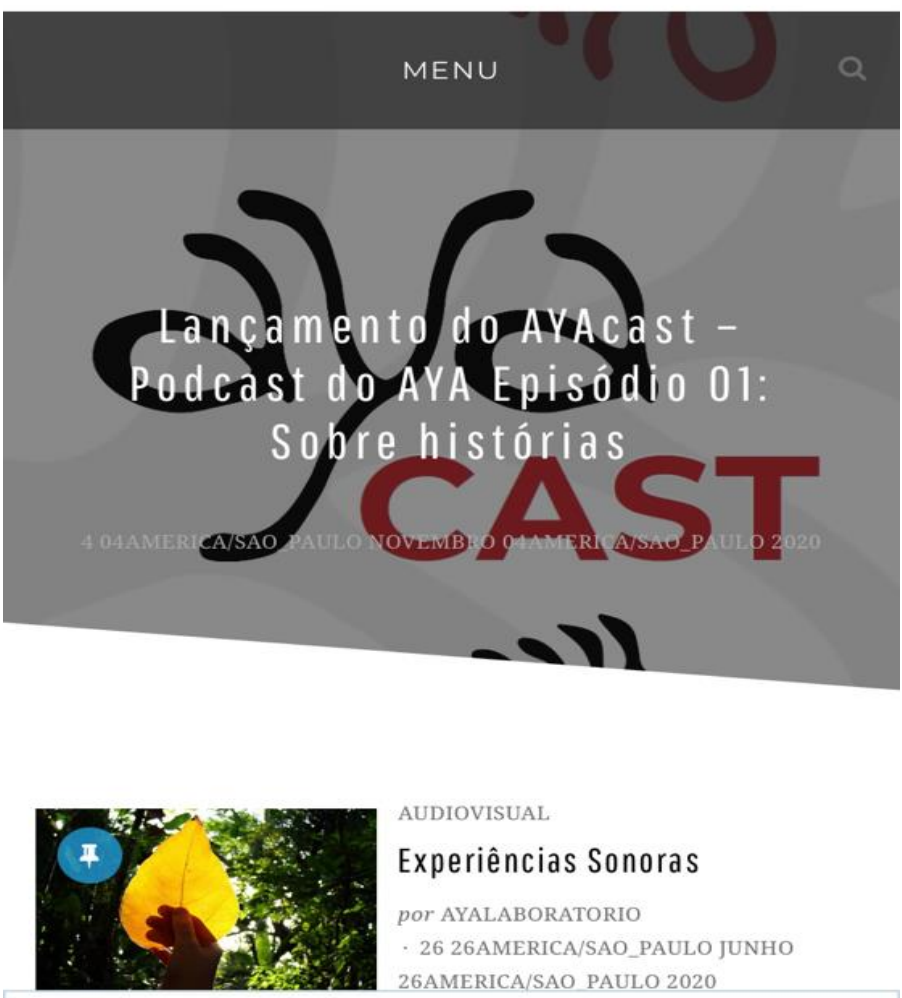

AUDIOVISUAL

Experiências Sonoras

por AYALABORATORIO

- 26 26AMERICA/SAO_PAULO JUNHO

26AMERICA/SAO PAULO 2020

$E_{+}$Seguir $\ldots$

Fonte: Extraído da AYA Biblioteca (2021)

No atributo - "Ubiquidade", a) não é percebido indicativos de que o ambiente utiliza tecnologias ubíquas e compreendemos que não há a necessidade de aplicação deste atributo. A ubiquidade representa a onipresença de computadores e da informática no modo de vida das pessoas. Isso não é visto apesar da AYA Biblioteca apresentar pervasividade, de maneira parcial, como é discorrido na próxima análise junto ao Quadro 4. 


\begin{tabular}{|c|c|c|}
\hline Atributo & Checklist & $\begin{array}{l}\text { Sim (S) } \\
\text { Não (N) } \\
\text { Parcialmente aplicável (P) } \\
\text { Não aplicável (NA) }\end{array}$ \\
\hline \multirow[t]{2}{*}{ Placemaking } & $\begin{array}{l}\text { a) Permite que os sujeitos informacio- } \\
\text { nais mantenham se orientados, construindo } \\
\text { sentido de localização. }\end{array}$ & S \\
\hline & $\begin{array}{l}\text { b) Atende finalidades, contextos e comuni- } \\
\text { dades específicas. }\end{array}$ & $S$ \\
\hline \multirow[t]{2}{*}{ Redução e Resiliência } & $\begin{array}{l}\text { a) Gerencia grandes conjuntos de informa- } \\
\text { ções e minimiza o estresse e frustração na } \\
\text { escolha de fontes de informação, serviços e } \\
\text { produtos. }\end{array}$ & $P$ \\
\hline & $\begin{array}{l}\text { b) O ambiente se adapta à sujeitos informa- } \\
\text { cionais específicos, necessidades específicas } \\
\text { e estratégias de busca contextuais. }\end{array}$ & $\mathrm{N}$ \\
\hline \multirow[b]{2}{*}{ Correlação } & $\begin{array}{l}\text { a) Sugere conexões relevantes entre ele- } \\
\text { mentos de informação, serviços e bens }\end{array}$ & $\mathrm{N}$ \\
\hline & $\begin{array}{l}\text { b) Ajuda os sujeitos informacionais a alcan- } \\
\text { çarem objetivos explicitados ou estimular } \\
\text { necessidades informacionais. }\end{array}$ & $\mathrm{S}$ \\
\hline \multirow[b]{2}{*}{ Pervasividade } & $\begin{array}{l}\text { a) Possui estrutura ecológica com uma di- } \\
\text { versidade de ambientes, meios, canais, } \\
\text { sistemas, tecnologias, etc. }\end{array}$ & $\mathrm{P}$ \\
\hline & $\begin{array}{l}\text { b) Permite a tendência de movimento, pro- } \\
\text { pagação, infiltração, difusão total ou parcial } \\
\text { através de vários ambientes, meios, canais, } \\
\text { sistemas, tecnologias, etc. }\end{array}$ & $P$ \\
\hline
\end{tabular}

Fonte: Adaptado de Vechiato, Oliveira e Vidotti (2016).

No atributo - "Placemaking", a) identificamos a possibilidade dos sujeitos se manterem orientados e direcionados de forma subjetiva, tendo um contraponto ao atributo wayfinding. $\mathrm{O}$ ambiente não gera elementos que indiquem caminhos aos sujeitos (wayfinding), porém permite um sentido de localização subjetivo (placemaking) pela navegação se basear basicamente em cliques em postagens e voltar para o início (homepage). O sujeito não é orientado a novos caminhos, e sim, depara-se com pistas para acesso a homepage; b) atende visto que o ambiente é direcionado a comunidades específicas, a população negra e a população indígena, sujeitos que desejam conhecer sobre questões étnico-raciais, antirracistas, entre outros.

No atributo - "Redução e Resiliência", a) o ambiente informacional digital gerencia parcialmente grandes conjuntos de informações e minimiza a frustração na escolha dos resultados, porém não permite uma busca facetada ou específica; b) não permite a busca em diferentes campos com especificidade de autor, título, ano, por exemplo.

No atributo - "Correlação", a) observamos que o ambiente não sugere conexões entre elementos de informação e serviços. Talvez isso seja por não existir a inserção de metadados para os materiais informacionais, ou seja, o sistema não consegue correlacionar assuntos por meio de palavras-chave ou cabeçalhos de assunto, por exemplo; b) contribui para estimular necessidades informacionais no sujeito por meio dos recursos de marketing utilizados no decorrer do website. Presenciamos que conforme navegamos, o ambiente divulga outras postagens para que o sujeito tome conhecimento, porém são gerais e não se correlacionam com a determinada postagem acessada pelo sujeito naquele momento. 
No atributo - "Pervasividade", a) observamos que possui parcialmente uma estrutura ecológica com o ambiente Laboratório de Estudos Pós-Coloniais e Decoloniais, sendo sua extensão. Existe caráter pervasivo quando acessamos a AYA Biblioteca pelo smartphone, por exemplo, tendo a difusão das mesmas informações dispostas no ambiente digital; b) o ambiente permite difusão total ao acessarmos por smartphones e tablets, tendo responsividade nesses meios/canais, sendo acessados pelo sujeito conforme a tecnologia que ele/a possua. Isso pode ser possibilitado pelos próprios recursos da plataforma WordPress. Por outro lado, se considerarmos a pervasividade, segundo Campos e Oliveira (2020), como uma ação que o sujeito inicia num canal e continua em outro canal, a AYA Biblioteca não contempla esse atributo. Talvez seja interessante, futuramente, a possibilidade de visitas guiadas ao Laboratório de Estudos Pós-Coloniais e Decoloniais da UDESC através da AYA Biblioteca, o que contribuiria para a inserção do sujeito no ambiente informacional analógico por meio da navegação no ambiente informacional digital. Certamente, recursos tecnológicos seriam demandados para a execução dessa funcionalidade.

\section{CONSIDERAÇÕES FINAIS}

A AYA Biblioteca situa-se no contexto das crescentes demandas de pesquisadores/as envolvidos na agenda antirracista. O ambiente é uma ação, em contexto digital, que auxilia na visibilidade da população negra e da população indígena, estabelecendo um instrumento educacional para o estudo das desigualdades sociais e raciais no Brasil. Isso permite que várias pessoas, independentemente do pertencimento étnico-racial, tenham acesso a materiais que contem a história e a contribuição desses grupos historicamente discriminados.

Recomendamos que nossa investigação seja direcionada aos/às gestores/as do ambiente e aos membros do Laboratório de Estudos Pós-Coloniais e Decoloniais da Universidade do Estado de Santa Catarina. Ficamos à disposição para diálogo e para a possível orientação de um domínio novo conforme identificamos na análise com o checklist, com vistas a facilitar a navegação e a encontrabilidade das informações pelos sujeitos.

Verificamos também a possibilidade de cadastro de seguidores através de e-mail para receber notificações dos materiais inseridos nesse ambiente informacional digital. No momento de execução dessa pesquisa, observamos 162 seguidores nesse ambiente. Observamos também a presença da AYA Biblioteca no Facebook, com 7.576 seguidores em sua página e no Instagram com 702 seguidores. Porém, existe uma incoerência nas nomenclaturas do ambiente informacional digital e das mídias sociais, tendo respectivamente o nome "AYA Biblioteca” e “@ayalaboratório” no Facebook e no Instagram. É necessária uma padronização de nomenclaturas, com a finalidade de auxiliar o sujeito na encontrabilidade dos canais provenientes do ambiente informacional digital. Também não há a indicação dessas mídias sociais no ambiente investigado neste artigo.

Também sugerimos que a AYA Biblioteca seja operacionalizada num ambiente ou plataforma que permita a inserção de metadados. A elaboração de um vocabulário controlado também é válida visando sempre a especificidade das buscas, a partir de instrumentos de controle terminológico. Isso faria com que o ambiente apresentasse sugestões ao sujeito ao digitar um determinado termo na aba de busca. Essa ferramenta de autocomplete é vista em websites e-commerce, no motor de busca Google e em determinadas bases de dados científicos, por exemplo.

Observamos a carência de ambientes informacionais digitais voltados a visibilidade de populações historicamente discriminadas, como a população negra e a população indíge- 
nas e, certamente, a AYA Biblioteca assume um papel particular para isso. Esse tipo de ambiente contribui para o conhecimento de materiais e recursos informacionais socioculturais que fomentam o diálogo antirracista, tão necessário no Brasil. Numa pesquisa subsequente, poderemos realizar uma observação não participante com sujeitos variados, a fim de aplicar tarefas a serem realizadas no ambiente da AYA Biblioteca. Uma ação dessa finalidade pode direcionar ainda mais a avaliação da satisfação e interação do/a usuário/a com esse ambiente informacional digital.

\section{REFERÊNCIAS}

CAMPOS, A. F.; OLIVEIRA, H. P. C. de. Traçados teóricos sobre Informação e Pervasividade. Revista ACB: Biblioteconomia em Santa Catarina, v. 25, n. 3, p. 448-461, 2020.

CAMPOS, A. F.; VECHIATO, F. L.. Avaliação dos ambientes informacionais do Núcleo Temático da Seca e do Semiárido da UFRN (NUT-Seca) sob a ótica do wayfinding no contexto da Encontrabilidade da Informação. In: SILVA, F. C. G da; LIMA, G. dos Santos. (Org.). Bibliotecári@s Negr@s: informação, educação, empoderamento e mediações. Florianópolis, SC: Rocha Gráfica e Editora, 2019. p. 557-574.

CAMPOS, A. F.; VECHIATO, F. L.. Construto para o conceito de wayfinding na Ciência da Informação. Informação \& Informação, v. 25, n. 4, p. 549-573, 2020.

MINAYO, M. C. de S.. (Org.). Pesquisa Social: teoria, método e criatividade. São Paulo: Petrópolis: Vozes, 2009.

MORESI, E. (Org.). Metodologia da pesquisa. Brasília: Universidade Católica de Brasília, 2003.

MORVILLE, P. Ambient Findability. Sebastopol: O'Reilly Media, 2005.

OLIVEIRA, H. P. C. de; AQUINO, M. de A. O conceito de informação etnicorracial na ciência da informação. Liinc em revista, v. 8, n. 2, 2012.

OLIVEIRA, H. P.C. de. Afrodescendência, memória e tecnologia: uma aplicação do conceito de informação etnicorracial ao projeto "A Cor da Cultura". 2009. 138 f. Dissertação (Mestrado em Ciência da Informação) - Centro de Ciências Sociais Aplicadas, Universidade Federal da Paraíba, João Pessoa, 2009.

RANGANATHAN, S R. As cinco leis da Biblioteconomia. Tradução de Tarcisio Zandone. Brasília: Briquet de Lemos, 2009.

ROA-MARTÍNEZ, S. M. Da information findability à image findability: aportes da polirrepresentação, recuperação e comportamento de busca. 2019. 235 f. Tese (Doutorado em Ciência da Informação) - Faculdade de Filosofia e Ciências, Universidade Estadual Paulista, Marília, 2019. 
VECHIATO, F. L. Encontrabilidade da Informação: contributo para uma conceituação no campo da Ciência da Informação. 2013. 206 f. Tese (Doutorado em Ciência da Informação) Faculdade de Filosofia e Ciências, Universidade Estadual Paulista, Marília, 2013.

VECHIATO, F. L.; OLIVEIRA, H. P. C. de; VIDOTTI, S. A. B. G.. Arquitetura da informação pervasiva e encontrabilidade da informação: instrumento para a avaliação de ambientes informacionais híbridos. Informação \& Tecnologia, v. 3, n. 1, p. 47-65, 2016.

VECHIATO, F. L.; VIDOTTI, S. A. B. G.. Encontrabilidade da informação. Coleção PROPG Digital: UNESP, 2014.

WEIRICH, R.; GASPARINI, I.; KEMCZINSKI, A.. Análise de Log para Avaliação do Comportamento do Aluno em um Ambiente de EAD na Web. In: Brazilian Symposium on Computers in Education (Simpósio Brasileiro de Informática na Educação-SBIE). 2007. p. 510-519. 